\title{
Trends and determining factors associated with adherence to antiretroviral therapy (ART) in Cameroon: a systematic review and analysis of the CAMPS trial
}

Lawrence Mbuagbaw ${ }^{1,2^{*}}$, Lehana Thabane ${ }^{2,3}$, Pierre Ongolo-Zogo ${ }^{1}$, David Yondo ${ }^{1}$, Stephen Noorduyn², Marek Smieja ${ }^{2,4}$ and Lisa Dolovich ${ }^{5}$

\begin{abstract}
Background: The benefits of antiretroviral therapy (ART) cannot be experienced if they are not taken as prescribed. Yet, not all causes of non-adherence are dependent on the patient. Having to pay for medication reduces adherence rates. Non- adherence has severe public health implications which must be addressed locally and globally. This paper seeks to describe the trends in adherence rates reported in Cameroon and to investigate the determinants of adherence to ART in the Cameroon Mobile Phone SMS (CAMPS) trial.

Methods: We conducted a systematic review of electronic databases (PubMed, Google Scholar, Web of Science, CINAHL, EMBASE and PSYCINFO) for publications on adherence to ART in Cameroon (from January 1999 to May 2012) and described the trend in reported adherence rates and the factors associated with adherence. Data were extracted in duplicate. We used multivariable analyses on the baseline data for 200 participants in the CAMPS trial to determine the factors associated with adherence in four models using different measures of adherence (more than $90 \%$ or $95 \%$ on the visual analogue scale, no missed doses and a composite measure: $100 \%$ on the visual analogue scale, no missed doses and all pills taken on time).

Results: We identified nine studies meeting our inclusion criteria. Adherence to ART in Cameroon has risen steadily between 2000 and 2010, corresponding to reductions in the cost of medication. The factors associated with adherence to ART in Cameroon are grouped into patient, medication and disease related factors. We also identified factors related to the health system and the patient-provider relationship. In the CAMPS trial, education, side effects experienced and number of reminder methods were found to improve adherence, but only using multiple reminder methods was associated with better adherence in all the regression models (Adjusted Odds Ratio [AOR] 4.11, 95\% Confidence Interval [CI] 1.89, 8.93; $\mathrm{p}<0.001$; model IV).
\end{abstract}

Conclusions: Reducing the cost of ART is an important aspect of ensuring adequate adherence rates. Using multiple reminder methods may have a cumulative effect on adherence to ART, but should be investigated further.

Keywords: Adherence, Antiretroviral therapy, Cameroon, Reminder methods, CAMPS

\footnotetext{
* Correspondence: mbuagblc@mcmaster.ca

${ }^{1}$ Centre for Development of Best Practices in Health (CDBPH), Yaoundé

Central Hospital, Avenue Henri Dunant, Messa, PO Box 87, Yaoundé,

Cameroon

${ }^{2}$ Department of Clinical Epidemiology and Biostatistics, McMaster University,

Hamilton, ON, Canada

Full list of author information is available at the end of the article
} 


\section{Background}

The advent of antiretroviral medication as a treatment for $\mathrm{HIV}$ is one of the most celebrated advances in medicine [1]. Antiretroviral therapy (ART) reduces viral loads to undetectable levels, and dramatically decreases morbidity and mortality. Decreasing serum viral load with antiretroviral medication also reduces mother to child transmission rates $[2,3]$. However, viral replication still occurs in reservoirs like lymph node or gastrointestinal T-cells even when viral loads are undetectable [4,5]. As such, good adherence is necessary to maintain prolonged viral suppression [5]. Non-adherence to HIV medication is a major reason for treatment failure, the development of resistant strains, and increased costs [6]. It is also one of the key predictors or determinants of success in the management of HIV/AIDS and the progression to AIDS and death $[7,8]$. Non-adherence reduces the immunologic potential of ART and is associated with drops in CD4-positive-T-lymphocyte counts [9-11]. Non-adherence has also been found to be associated with increased hospitalisations and longer hospital stays $[10,12]$. Initial worries in the scientific community about non-adherence in sub-Saharan Africa were dispelled when research findings demonstrated similar or higher rates of adherence than in the developed world [13]. However, only a third of people living with HIV (PLHIV) take their medication as prescribed [1]. Nonadherence leads to increased viremia which might lead to increased transmissibility and consequently a higher incidence of HIV. High risk activity may also lead to the transmission of resistant strains to newly infected individuals, thereby reducing their therapeutic options [14,15]. Adherence to ART has clinical and public health implications, and should therefore be addressed on global and local levels.

\section{Defining adherence}

Adherence can be narrowly defined as the "extent to which patients take medications as prescribed by their health care providers" [16], or more broadly as the "the extent to which a person's behaviour-taking medication, following a diet, or executing lifestyle changes, corresponds with agreed recommendations from a health care provider" [1]. The former definition refers to compliance with medication as prescribed by the provider while the latter goes beyond medication to include all the recommendations jointly agreed upon by both provider and client to improve health care. The latter definition also highlights or acknowledges additional factors such as diet or lifestyle which may affect adherence. It also recognises that the client may not agree with the recommendations of the health care provider. Such factors are even more relevant in HIV where dietary restrictions are required for the uptake of certain medications $[17,18]$ and that certain lifestyles (e.g. substance abuse) can lead to non- adherence to ART [19]. In this paper, all degrees of adherence which are not optimal are referred to as non-adherence.

The factors associated with adherence to ART exist in many categories, defined in literature $[1,16,19]$ :

Patient factors such as substance abuse, being male (i.e. gender), depression, lower levels of education, lack of self efficacy, extreme anxiety, extreme pain, no change in health status despite ART and non-white race are significantly associated with non-adherence $[1,19]$. Medication factors like dose frequency, pill burden, type of drug, inability to take medication when away from home, food requirements, side effects are also responsible for less than optimal adherence $[1,19]$. In other words the complexity of the regimen and its sideeffects are associated with non-adherence.

Provider-related factors such as a poor patient-health care provider relationship can affect the patient's overall satisfaction and trust in the provider. The quality of these relationships is significantly associated with better adherence [1,20,21].

Disease characteristics, notably stage and duration of HIV infection, symptoms experienced and the presence of opportunistic infections play a role in adherence to ART. HIV related symptoms like nausea may impede a patient from swallowing pills. Some studies report that patients who have experienced an opportunistic infection tend to be more adherent than those who have not [1,22,23].

Clinical setting and health system factors may influence use of services and adherence [19].

\section{Adherence to ART in Cameroon}

Cameroon has one of the highest rates of HIV in west and central Africa, with $5.3 \%$ of the adult population living with HIV. Of these, only $30 \%$ are receiving ART [24]. Adherence to ART in Cameroon has changed over the years for a multitude of reasons. Health system changes like the decentralization of HIV treatment centres and the subsidy of costs of medication and testing over the years have contributed to the variations in the reported adherence rates. A substantial reduction in costs occurred in 2004 [25] and ART has been provided for free since 2007 [26]. As a result, the designs and the contexts of the studies reporting rates of adherence to ART in Cameroon also vary. The set of similar and varying contextual factors in Cameroon make it a worthwhile case study to examine adherence to ART and learn lessons that could be applied across the country. Adherence rates in Cameroon have been measured using patient reports, pharmacy refill data, attendance at scheduled visits and blood testing [25-35]. These different methods have spawned adherence rates varying from $10.1 \%$ to $97.5 \%$, between 2000 and 2010. Faced 
with these enormous discrepancies, we sought to use data from a recent trial [36] to describe adherence to ART and the associated determining factors. Adherence rates are not only a predictor of treatment success, but also an indication of how many resources should be invested in adherence enhancement research and practice. This cannot be done without stable estimates for adherence or a comprehensive list of locally relevant determinants.

Additionally, in a changing world where new methods and technologies arise to improve adherence rates, and levels of stigma are declining, there may be a shift in patients' attitudes and practices related to adherence.

The objectives of this paper are:

- to review the literature on adherence in Cameroon with specific emphasis on ART adherence rates and its correlates or determinants, and

- to report the factors associated with adherence to ART at baseline in the Cameroon Mobile Phone SMS trial (CAMPS;36).

\section{Methodology}

Literature review of ART adherence rates in Cameroon

We searched electronic databases (PubMed, Google Scholar, Web of Science, CINAHL, EMBASE and PSYCINFO) for publications on adherence to ART in Cameroon (from January 1999 to May 2012) using appropriate combinations of keywords such as Cameroon, Cameroun (French), adherence, compliance, antiretroviral therapy, antiretroviral treatment and HIV. ART was introduced in Cameroon in 1999 [37]. No language restrictions were set. Citations were screened and full text obtained if they reported any measure of adherence to ART in Cameroonian subjects. Completeness and adequacy of reporting in the selected studies were assessed in duplicate by noting their compliance to the 22-item Strengthening the Reporting of Observational Studies in Epidemiology (STROBE) checklist [38]. Data were also extracted in duplicate: citation details; year study was conducted, city in which study was conducted, adherence rate, method of measure of adherence, study design, sample size and the cost of ART at the time. Discrepancies were resolved by discussion. We examined the evolution of adherence rates taking into account the above characteristics. We also identified the reported factors associated with adherence and classified them as patient variables, medication variables, patient-provider relationship and health system characteristics. These categories have previously been identified in literature $[16,19]$. No statistical pooling was performed. The factors associated with adherence were extracted only if they resulted from multivariable analyses. The reported odds ratios and p-values were used to confirm the associations reported.

\section{Adherence to ART in CAMPS}

We conducted a cross-sectional analytical study based on the baseline data for the Cameroon Mobile Phone SMS (CAMPS) trial [36]. Data were collected from a subset of patients (eligible for the trial) aged 21 or older, who owned mobile phones and who agreed to take part in the trial. The independent variables included sociodemographics like age (in years), gender (male or female), level of education (none and primary or secondary and university), disclosure of status to family members (family aware or not aware of HIV status); clinical features like presence or absence of an opportunistic infection, Centers for Disease Control and Prevention (CDC; [39]) classification (categorised as AIDS defining condition or not), regimen (first line or second line), duration on treatment (in months); the number of drug side-effects experienced and the number of recall methods used. All the independent variables were those reported in literature and collected for the CAMPS trial [36]. The dependent variables were adherence measured using a visual analogue scale (0-100), self report on the number of missed doses and whether the doses were taken on time in the week preceding the interview. We also designed a composite measure of adherence based on all three measures, which we dichotomized as adherent (VAS=100; number of missed doses $=0$; all doses taken on time $=y e s)$ and non-adherent $(\mathrm{VAS}<100$; missed doses $>0$; all doses taken on time $=$ no).

We performed multivariable logistic regression with adherence (dependent variable) dichotomized at the VAS cut-offs of 90 and 95\% (Model I and II). These cut-off points represent the levels of adherence at which sustained viral suppression can occur [5], and those often used in literature [40,41]. We also analyzed the data using the self reports of adherence as the dependent variable, in which case one or more missed doses was considered as non-adherence and no missed dose was considered as good adherence (Model III). We repeated these analyses using the composite measure of adherence (Model IV). The interaction between independent variables was investigated based on associations reported in the general literature and specifically for Cameroon. Variables were introduced into the model in blocks defined by the following categories: socio-demographic, disease-related and medication-related. Model fit was assessed using the Hosmer and Lemeshow goodness of fit statistic [42].

Data were analysed using Predictive Analytic Software (PASW) Version 17.0 (SPSS, Inc., 2009, Chicago, IL, USA). Statistical significance was set at alpha $=0.05$. Adjusted odds ratios (AOR), 95\% confidence intervals (CI) and p-values are presented. The forest plot was drawn using Stata Statistical Software (STATA) Release 12 (StataCorp LP, 2011, College Station, TX, USA). 


\section{Results}

Literature review

We identified 9 studies conducted between 2000 and 2010 which reported adherence rates in Cameroon. The mean number of reported items on the STROBE checklist was 19.7 (standard deviation [SD] 1.38). Data from the CAMPS trial was included in the analysis [36]. Five of them were conducted in Yaoundé, the capital city of Cameroon. The characteristics of these studies are reported in Table 1 . We observed an increasing trend in adherence rates over time, which corresponds to the reductions in cost of ART (Figure 1). Two studies were outliers to this quasi-linear relationship. The first was Kouanfack et al. [27], which reported high adherence rates $(88.7 \%$ and $97.5 \%$, using biological markers and self report respectively). This study was a drug trial and participants received medication free of charge at a time when medication costed $51.2 \mathrm{USD} /$ month. The second, Mosoko et al. [25], reported very low adherence rates (10.1\% using hospital records of the number of scheduled clinic visits attended). These data may be affected by inaccuracies in hospital records (incompleteness was handled using imputation techniques); participants who lived far away were sometimes given medication for more than one month; patients who lived in the nearby city of Douala had other ART opportunities and this measure (scheduled visits) considers all deaths and lost to follow-up as non-adherent. Ideally, the cases of death should be excluded from the denominator. The other study using attendance of scheduled visits [29] also reported low adherence rates $(<50 \%)$.

\section{Determinants of, and factors associated with ART adherence}

In addition to the nine papers that reported adherence rates, we identified two papers which reported on the determinants of adherence to ART. These studies were conducted in cross-national cohorts of patients from Cameroon, the Democratic Republic of Congo and Burundi (Table 2). These papers were provided additional information on factors associated with adherence [34,35]. They were not used in the trend analysis.

These factors were found to reduce adherence to ART: binge drinking, drug use, tobacco use, lack of family support, experience of stigma, switching regimen, advanced stage of disease, cost of care, distance from clinic, large hospital size and no task shifting from physician to other staff [25,28,30-35].

These factors increased adherence to ART: Female gender, age greater than 49 years, higher levels of education, positive perceptions of treatment, high motivation, using reminder methods, satisfaction with information provided by physician, higher CD4 count at initiation of ART, and being transferred-in from another clinic [30,31,33-35].

High monthly income [31,32] and increased duration on medication $[30,33,35]$ were both reported to either increase or reduce adherence.

Table 1 Characteristics of studies reporting adherence to ART in Cameroon

\begin{tabular}{|c|c|c|c|c|c|c|}
\hline Reference & Year & City & $\begin{array}{l}\text { Study design } \\
\text { (sample size) }\end{array}$ & $\begin{array}{l}\text { Adherence } \\
\text { rate }\end{array}$ & Method & $\begin{array}{l}\text { Cost of ART/month for that } \\
\text { year in USD* }\end{array}$ \\
\hline $\begin{array}{l}\text { Laurent } \\
\text { et al. }\end{array}$ & $2000-2003$ & Douala & $\begin{array}{l}\text { Cross-sectional } \\
\text { retrospective (788) }\end{array}$ & $<50 \%^{\mu}$ & $\begin{array}{l}\text { Scheduled visits } \\
\text { attended }\end{array}$ & 128 \\
\hline $\begin{array}{l}\text { Kouanfack } \\
\text { et al. }\end{array}$ & $2002-2003$ & Yaoundé & Prospective cohort (60) & $\begin{array}{l}88.7 \% \\
(97.5 \%)\end{array}$ & $\begin{array}{l}\text { Biological markers, } \\
\text { (Self Report) }\end{array}$ & 51.2 (free for participants) \\
\hline $\begin{array}{l}\text { Mosoko } \\
\text { et al. }\end{array}$ & $2002-2005$ & Limbe & $\begin{array}{l}\text { Cross-sectional } \\
\text { retrospective }^{a}(2920)\end{array}$ & $10.1 \%$ & $\begin{array}{l}\text { Scheduled visits } \\
\text { attended }\end{array}$ & 51.2 \\
\hline $\begin{array}{l}\text { Boyer et al. } \\
\text { [28] }\end{array}$ & 2006 & Yaoundé & Cross-sectional (532) & $56.6 \%$ & Self Report ${ }^{\beta}$ & 12.8 \\
\hline $\begin{array}{l}\text { Rougemont } \\
\text { et al. }\end{array}$ & 2006 & Yaoundé & Prospective cohort (312) & $64 \%(78 \%)$ & $\begin{array}{l}\text { Pharmacy data (Self } \\
\text { report) }\end{array}$ & 12.8 \\
\hline $\begin{array}{l}\text { Boyer et al. } \\
{[32]}\end{array}$ & $2006-2007$ & $\begin{array}{l}\text { Multiple } \\
\text { locations }\end{array}$ & Cross-sectional (3151) & $53.9 \%$ & Self report ${ }^{\beta}$ & 12.8 \\
\hline Roux et al. & $2006-2008$ & Yaoundé & Prospective cohort (401) & $61-73 \%$ & Self report ${ }^{\beta}$ & 12.8 \\
\hline Mahy et al. & $2007-2008$ & Tokombere & Cross-sectional (56) & $95 \%(80 \%)$ & $\begin{array}{l}\text { self report }{ }^{\beta} \\
\text { (Pharmacy data) }\end{array}$ & 0 \\
\hline $\begin{array}{l}\text { Mbopi-Keou } \\
\text { et al. }\end{array}$ & 2010 & Dschang & Cross-sectional (356) & $\begin{array}{l}80.2 \% \\
(48.7)\end{array}$ & $\begin{array}{l}\text { Self report }{ }^{\beta} \\
\text { (Pharmacy data) }\end{array}$ & 0 \\
\hline CAMPS & 2010 & Yaoundé & Cross-sectional (200) & $90.5 \%$ & Self report ${ }^{\beta}$ & 0 \\
\hline
\end{tabular}

*Costs vary per regimen, the highest costs are reported.

a Cross- sectional analysis of previously collected data without planning for needs of an investigation.

${ }^{\beta}$ All methods in which all information used to measure adherence was obtained by interviewing the participant with either one question or a series of questions.

${ }^{\mu} 50 \%$ was imputed to represent the trend graphically. 


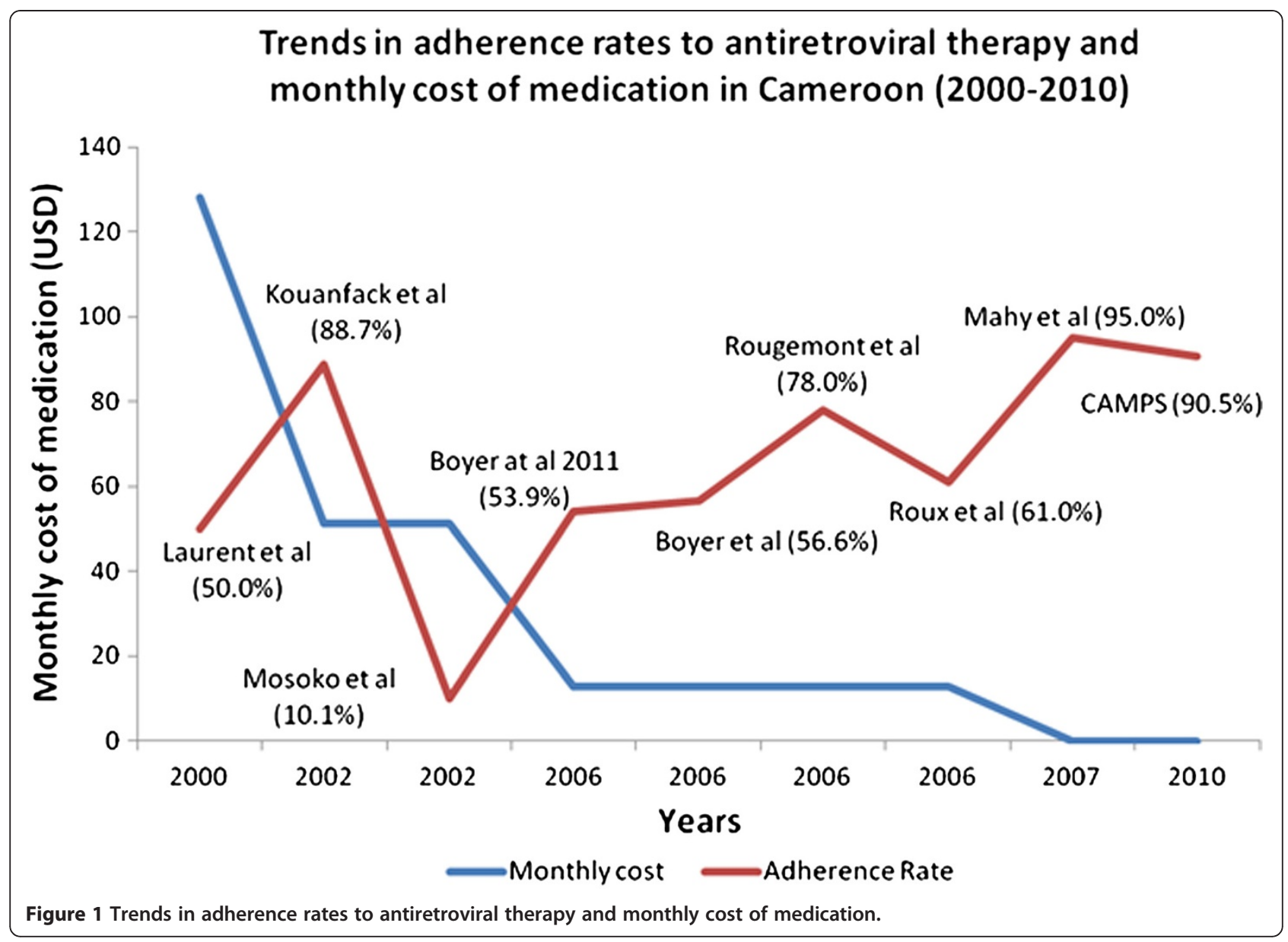

Factors associated with adherence to ART at baseline in the CAMPS Trial

In this sample of 200 adults, one fifth was older than 50 years, three-quarters were female, $98 \%$ had at least primary education, and $90 \%$ reported that their families were aware of their HIV status. The rest of their characteristics are reported in Table 3. All the factors associated with adherence that were collected in this data set were used in the regression analysis. The baseline data for participants in the CAMPS trial are reported in Table 3.

In the first model, we dichotomized adherence using the VAS at $95 \%$. Using multiple recall methods was significantly associated with adherence $>95 \%$ (AOR 6.7, 95\% CI 2.69, 16.56; $\mathrm{p}<0.001)$. In our second model, adherence was dichotomized at $90 \%$. Female gender was associated with adherence $>90 \%$ (AOR 0.28, 95\% CI $0.09,0.90 ; \mathrm{p}=0.032$ ), while secondary education (AOR, 4.4 95\% CI 1.64, 11.92; $\mathrm{p}=0.003)$ and multiple recall methods (AOR, 7.89 95\% CI 3.22, 19.33; p<0.001) were associated with adherence $>90 \%$. In the third model we used the number of missed doses as our measure of adherence. Experiencing more side effects (AOR 2.25, 95\%
CI 1.13, 4.50; $\mathrm{p}=0.021)$ and using multiple recall methods increased the odds for not missing doses (AOR 7.28, 95\% CI 3.06, 17.32; $\mathrm{p}<0.001)$. In our last model we used a composite measure of adherence that incorporated the VAS, number of missed doses and timing of doses. Only the use of multiple recall methods was associated with adherence (AOR 4.11, 95\% CI 1.89, 8.91; $\mathrm{p}<0.001$ ). The Hosmer and Lemeshow goodness-of-fit statistic for all the four models had p-values greater than 0.05 implying a good fit [42]. These models are displayed in Figure 2.

\section{Discussion}

By reviewing the literature on adherence rates in Cameroon, and analysing a new data set we have produced an explanatory account of the trends in adherence observed and the reported determinants. We also identified another plausible means of enhancing adherence to ART: using multiple reminder methods.

Despite the different study designs, locations and sample sizes there is a clear improvement in adherence rates over time irrespective of how it is measured. This finding confirms and supports health policies that reduce 
Table 2 Factors associated with adherence to ART in literature reports from Cameroon

\begin{tabular}{|c|c|}
\hline Factors & Reference (findings) \\
\hline \multicolumn{2}{|l|}{ Patient variables } \\
\hline Female gender & Rougemont et al. $(\uparrow)$ \\
\hline Age $>49$ years & Newman et al.* $(\uparrow) ;$ Freeman et al.**( $\uparrow)$ \\
\hline High monthly income & Rougemont et al. $(\downarrow)$; Boyer et al. ([28] ; $\uparrow)$ \\
\hline Education & Freeman et al. $(\uparrow)^{*}$ \\
\hline Binge drinking & Boyer et al. $([32] ; \downarrow)$; Roux et al. $(\downarrow)$; Newman et al. $(\downarrow)^{*}$ \\
\hline Drug use & Freeman et al. $(\downarrow)^{*}$ \\
\hline Tobacco use & Freeman et al. $(\downarrow)^{*}$ \\
\hline Lack of family support for adherence & Boyer et al. $([32] ; \downarrow)$; \\
\hline Experiencing discrimination and stigma & Boyer et al. ([32]; $\downarrow)$; \\
\hline Positive perception of treatment & Roux et al. $(\uparrow)$ \\
\hline Being transferred-in to HIV clinic & Mbopi-Keou ( $\uparrow)$ \\
\hline \multicolumn{2}{|l|}{ Medication variables } \\
\hline Switching regimen & Boyer et al. ([32]; $\downarrow)$; \\
\hline High motivation & Roux et al..( $\uparrow$ \\
\hline Using a reminder method & Roux et al..( $\uparrow$ \\
\hline \multicolumn{2}{|l|}{ Patient Provider Relationship } \\
\hline Satisfaction with information provided by physician & Roux et al..( $\uparrow$ \\
\hline \multicolumn{2}{|l|}{ Disease characteristics } \\
\hline Advanced stage of disease & Rougemont et al. $(\downarrow)$; Roux et al.. $(\uparrow)$ \\
\hline Increased duration on medication & Roux et al.( $\downarrow)$; Freeman et al. $(\uparrow)^{*}$ Mbopi-Keou $(\uparrow)$ \\
\hline Higher $\mathrm{CD}^{*}$ count at initiation of $\mathrm{ART}{ }^{\beta}$ & Mbopi-Keou ( $\uparrow)$ \\
\hline \multicolumn{2}{|l|}{ Health System/clinic Characteristics } \\
\hline Cost of care/Having to pay for care & Mosoko et al.( $\downarrow)$, Boyer et al. ([32] ; $\downarrow)$; Boyer et al. ([28] ; $\downarrow)$ Laurent et al. ( $\downarrow)$ \\
\hline Increased distance from clinic & Mosoko et al. ( $\downarrow)$ \\
\hline Large hospital size & Boyer et al. $([32] ; \downarrow)$; \\
\hline No task shifting from physician to other staff & Boyer et al. ([32]; $\downarrow)$; \\
\hline
\end{tabular}
females from Cameroon, Burundi and the Democratic Republic of Congo; ${ }^{*} \mathrm{CD} 4$-positive-T-lymphocyte; ${ }^{\beta}$ Antiretroviral therapy.

the cost of care to improve access and use. This is also in line with studies reporting that the main hindrances to adherence in Africa are related to health system weaknesses such as inadequate supply, human resource shortages and poor infrastructure $[29,32]$.

The determinants of adherence to ART identified in the Cameroonian literature are a subset of factors identified elsewhere [19]. However, there are discrepancies as to the role of monthly income and duration on ART on adherence. Boyer et al. [32] reported better adherence with a higher monthly income, while Rougemont et al. [31] reported the contrary. Both studies were initiated in the same period (2006) and therefore the cost of medication is unlikely to be the reason for this discrepancy. On the other hand Boyer et al. conducted a multisite (27 sites) study with a larger sample size $(\mathrm{n}=3151)$ compared to Rougemont et al. $(\mathrm{n}=312)$ in a single site. The results from Boyer et al. may be more plausible in the
Cameroonian context where, apart from free ART, other related services are still funded by out-of-pocket payments and having to pay for care has been identified as a cause of non-adherence $[25,28,29,32]$. The larger sample is also more likely to have more accurate and generalizable data, especially since one of the sites included in Boyer et al. is the same site where the Rougemont study was conducted.

Roux et al. [30] noted a drop in adherence rates with increased duration on ART while Freeman et al. and Mbopi-Keou et al. [33,35] noted the contrary. However, these two samples differ greatly. Roux et al. describe a multisite study in the Centre region of Cameroon, in 401 PLHIV over two years. Freeman et al. describe a crossnational cohort of 8419 women from Cameroon, Burundi and the Democratic Republic of Congo followed up for two years. Female gender has been reported as a factor for better adherence [31] and this discrepancy may explain the interaction between gender and duration on 
Table 3 Baseline characteristics of participants in the CAMPS trial

\begin{tabular}{|c|c|}
\hline Variable & Statistic \\
\hline Age (years) : mean (SD) ${ }^{\alpha}$ & $40.1(10.10)$ \\
\hline $21-49$ & $157(79.3)$ \\
\hline $50+$ & $41(20.7)$ \\
\hline \multicolumn{2}{|l|}{ Gender: $n$ (\%) } \\
\hline Female & $147(73.5)$ \\
\hline \multicolumn{2}{|l|}{ Level of education: $\mathbf{n}(\%)$} \\
\hline None or primary & $78(39.0)$ \\
\hline Secondary or university & $122(61.0)$ \\
\hline Family aware of HIV status: $\mathbf{n}(\%)$ & $180(90.0)$ \\
\hline Presence of an opportunistic infection: $n(\%)$ & $62(31.0)$ \\
\hline $\mathrm{BMI}:$ mean $(\mathrm{SD})^{\beta}$ & $25.2(4.00)$ \\
\hline Underweight & $4(2.2)$ \\
\hline Normal & $90(48.6)$ \\
\hline Overweight & $91(49.2)$ \\
\hline CDC* classification - AIDS defining illness§:n (\%) & $146(73.0)$ \\
\hline \multicolumn{2}{|l|}{ Regimen: $\mathrm{n}(\%)^{\delta}$} \\
\hline First line & $179(90.9)$ \\
\hline Second line & $18(9.1)$ \\
\hline Duration on ART (months): median (Q1, Q3) ${ }^{a}$ & $28.5(9.0,48.0)$ \\
\hline CD4 (cells per $\mathrm{mm}^{3}$ ): median (Q1, Q3) & $336.0(200.5,487.7)$ \\
\hline \multicolumn{2}{|l|}{ Adherence } \\
\hline Visual Analogue Scale: mean (SD) ${ }^{\varepsilon}$ & $90.5(12.76)$ \\
\hline Number of missed doses: mean (SD) ${ }^{\mu}$ & $1.0(0.00)$ \\
\hline No missed doses: $\mathbf{n}(\%)$ & $127(65.1)$ \\
\hline Treatment taken on time: $\mathrm{n}(\%)$ & $108(54.0)$ \\
\hline \multicolumn{2}{|l|}{ Reasons for missing doses: $\mathbf{n}(\%)$} \\
\hline Forgot & $54(27.0)$ \\
\hline Out of home & $23(11.5)$ \\
\hline Out of tablets & $7(3.5)$ \\
\hline Too busy & $8(4.0)$ \\
\hline Side effects & $2(1.0)$ \\
\hline Other reason & $5(2.5)$ \\
\hline \multicolumn{2}{|l|}{ Medication side effects experienced: $\mathbf{n}(\%)$} \\
\hline None & $127(63.5)$ \\
\hline One & $43(21.5)$ \\
\hline Two & $30(15.0)$ \\
\hline \multicolumn{2}{|l|}{ Reminder methods: $\mathbf{n}(\%)^{¥}$} \\
\hline None & $49(25.7)$ \\
\hline One & $125(65.4)$ \\
\hline Multiple & $17(8.5)$ \\
\hline
\end{tabular}

SD: standard deviation; BMI: body mass index; ${ }^{*}$ Centres for Disease Control, $\S=C D C$ classifications: A3, B3, C1, C1, C3 [39]; $\alpha=2$ missing; $\delta=3$ missing; $\beta=15$ missing; $\varepsilon=10$ missing $¥=9$ missing; $\mu=5$ missing.

The reminder methods reported were: personal verbal reminders by individuals, phone alarms, meal times, timing with TV shows and watches. medication. Mbopi-Keou et al. suggest that this trend might be the effect of continuous psycho-social support [33].

One study reported higher levels of adherence for patients who initiated ART with high levels of CD4-positive-T-lymphocytes [33]. This finding is in favor of earlier initiation of ART. Why patients who were transferred to the clinic would have better adherence rates is unclear. However, if they left their previous clinics due to service provision issues or unsatisfactory interactions with clinic staff, the latter clinic may provide a more favorable environment for adherence.

Using multivariable analysis we identified gender, education, side effects experienced, and number of reminder methods as factors that affect adherence rates.

The male gender has often been reported as the most likely to be non-adherent, maybe because males are more likely to engage in other behaviours that influence adherence such as binge drinking, tobacco use and drug use [19]. This effect was not found in all models and is not consistent across studies [19].

Level of education seems to play a role in adherence behaviour. A significant difference in adherence exists between people with secondary and those with no education. Further increments in educational level show no effect. This may imply that as concerns adherence to ART there are no benefits to be gained from very high levels of education. The benefits of education on adherence to ART can be obtained from secondary education. This effect was not consistent across all models.

Our findings regarding side effects are contrary to what is reported in literature. People who experienced more side-effects were more likely to be adherent. No other Cameroonian studies have identified side effects as a determinant for adherence to ART. In the CAMPS trial only $1 \%$ of those who missed doses reported side effects to be the reason for not taking medication (Table 3).

Only the number of reminder methods was associated with adherence in all the models. Another Cameroonian study reported the use of reminder methods to be associated with better adherence [30]. This is the first study to show that multiple reminders may have a cumulative effect. A randomized clinical trial in Kenya found alarms to have no effect on virological outcomes [43]. Simple electronic alarms are not as complex as the reminder methods described in this population (personal verbal reminders by individuals, phone alarms, meal times, timing with TV shows and watches). Other studies have reported the use of mobile phone beeps and prayer times by Muslims to remind them of when to take their medication [44]. The use of multiple and varied reminder methods may address other causes of non-adherence like forgetfulness and lack of social support. 


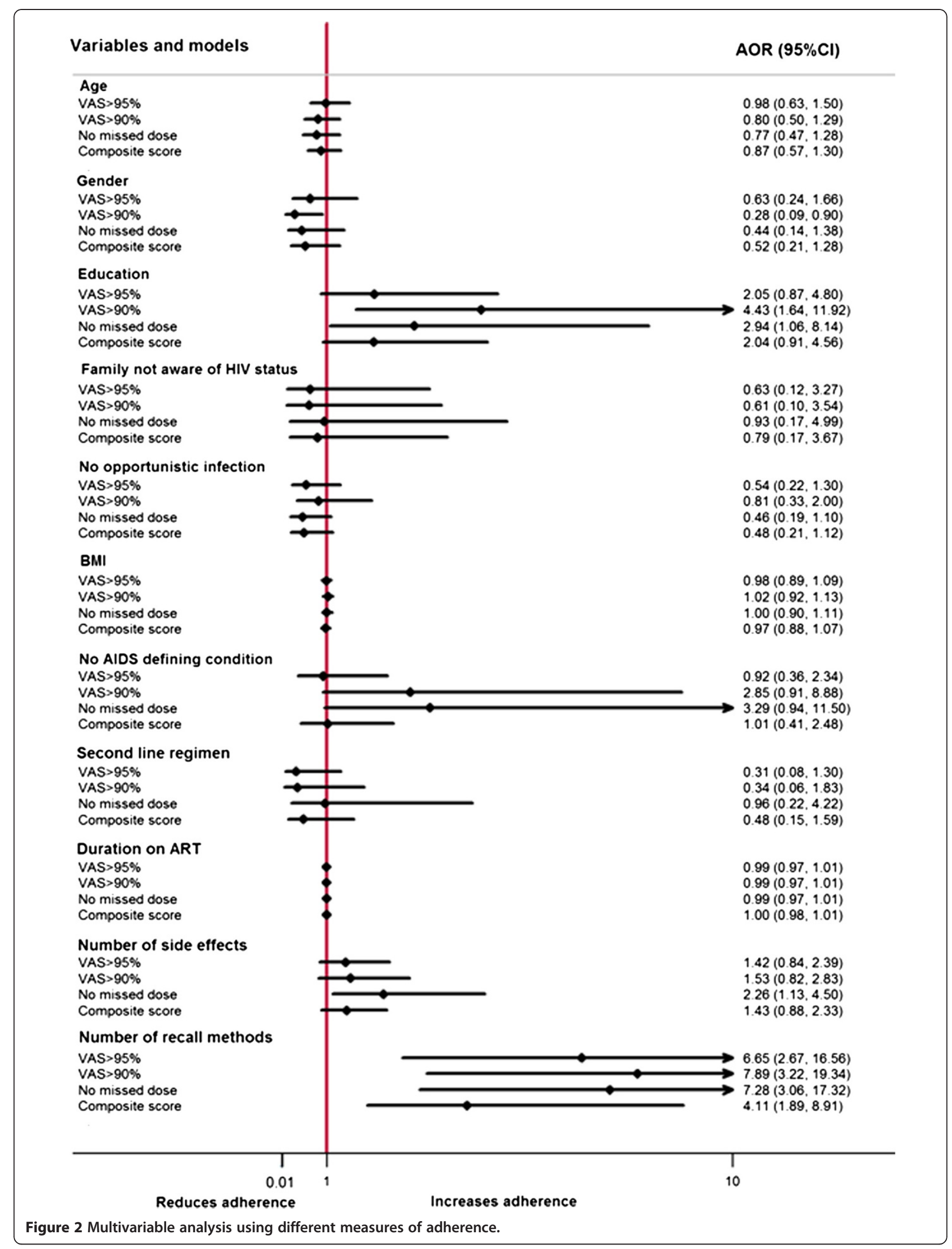


The difference in the four models suggests that the factors associated with adherence depend somewhat on how adherence is defined and the thresholds for acceptable adherence. Different levels of adherence are associated with different factors. It is unclear how this issue can be resolved without a uniform and validated tool for measuring adherence rates in clinical practice or research, as all methods have their advantages and flaws [16,45]. Self reported adherence is by far the most popular method used, but how it is used varies greatly $[16,46]$. On the one hand, a simple visual analogue scale can be used to situate a patient's adherence; and on the other a series of questions related to number of pills, timing, missed doses and identification of pills, all fall under the canopy of self report.

In low resource settings, self report, attendance-based and dispensing-based adherence measuring methods can predict important clinical outcomes [46] and should be collected routinely. Some measure of drug availability or the occurrence of drug stock-outs should be documented to explain trends in adherence behaviours.

Both sections of this paper may have limitations. Even though we observed an increasing trend in adherence as the cost of ART reduces, other temporal factors may contribute to this trend, notably health system improvements over the years and reductions in stigma and discrimination. These factors are reported as potential threats to optimal adherence and are very likely to change over time. The availability and use of reminder methods like mobile phones may also enhance adherence over time [25,32]. Participants in this study (CAMPS) may not adequately represent all the people living with HIV, but a subgroup who are already on ART, and who own mobile phones. Even though mobile phone ownership is widespread in Cameroon, those who own them may differ significantly from those who don't.

\section{Conclusions}

A prerequisite to optimal adherence is the availability of free or cheap medication. Irrespective of how it is measured, adherence rates tend to improve as the cost of medication is reduced. Improved financing mechanisms for ART are an important way of ensuring adequate adherence and improving outcomes for people living with HIV. Multiple and varied reminder methods are more likely to improve adherence than any single method alone. Further research is required to elucidate what combinations of reminder methods can produce the most desirable effects.

\section{Competing interests}

The authors declare that they have no competing interests.

\section{Authors' contributions}

$L M$ and LT conceived of the study; LM and SN performed the searches and extracted the data; LM, LT, SN, POZ, DY, LD and MS provided intellectual content and revised several versions of the manuscript. All authors read and approved the final manuscript.

\section{Funding}

This study was funded in part by the CIHR Canadian HIV Trials Network (CTN).

\section{Author details}

${ }^{1}$ Centre for Development of Best Practices in Health (CDBPH), Yaoundé Central Hospital, Avenue Henri Dunant, Messa, PO Box 87, Yaoundé, Cameroon. ${ }^{2}$ Department of Clinical Epidemiology and Biostatistics, McMaster University, Hamilton, ON, Canada. ${ }^{3}$ Biostatistics Unit, Father Sean O'Sullivan Research Centre, St Joseph's Healthcare, Hamilton, ON, Canada. ${ }^{4}$ St. Joseph's Healthcare Hamilton, Hamilton, ON, Canada. ${ }^{5}$ Department of Family Medicine, McMaster University, McMaster Innovation Park, Hamilton, ON, Canada.

Received: 13 September 2012 Accepted: 18 December 2012

Published: 19 December 2012

\section{References}

1. WHO: Adherence to long-term therapies: Evidence for action; 2003. Available from: http://www.who.int/chp/knowledge/publications/ adherence_report/en/ (Accessed 27 May 2012).

2. Vernazza PL, Troiani L, Flepp MJ, Cone RW, Schock J, Roth F, Boggian K, Cohen MS, Fiscus SA, Eron JJ: Potent antiretroviral treatment of HIV-infection results in suppression of the seminal shedding of HIV. The Swiss HIV Cohort Study. AIDS 2000, 14:117-121.

3. Sperling RS, Shapiro DE, Coombs RW, Todd JA, Herman SA, McSherry GD, O'Sullivan MJ, Van Dyke RB, Jimenez E, Rouzioux C, Flynn PM, Sullivan JL, Pediatric AIDS Clinical Trials Group Protocol076 Study Group: Maternal viral load, zidovudine treatment, and the risk of transmission of human immunodeficiency virus type 1 from mother to infant. N Engl J Med 1996, 335:1621-1629.

4. Montaner JS, Reiss P, Cooper D, Vella S, Harris M, Conway B, Wainberg MA, Smith D, Robinson P, Hall D, et al: A randomized, double-blind trial comparing combinations of nevirapine, didanosine, and zidovudine for HIV-infected patients: the INCAS Trial. Italy, The Netherlands, Canada and Australia Study. JAMA 1998, 279:930-937.

5. Paterson DL, Swindells S, Mohr J: Adherence to protease inhibitor therapy and outcomes in patients with HIV infection. Ann Intern Med 2000, 133:21-30.

6. Gill CJ, Hamer DH, Simon JL, Thea DM, Sabin LL: No room for complacency about adherence to antiretroviral therapy in sub-Saharan Africa. AIDS 2005, 19:1243-1249.

7. de Olalla Garcia P, Knobel H, Carmona A, Guelar A, Lopez-Colomes JL, Cayla JA: Impact of adherence and highly active antiretroviral therapy on survival in HIV-infected patients. J Acquir Immune Defic Syndr 2002, 30:105-110.

8. Bangsberg DR, Perry S, Charlebois ED, Clark RA, Roberston M, Zolopa AR, Moss A: Non-adherence to highly active antiretroviral therapy predicts progression to AIDS. AIDS 2001, 15:1181-1183.

9. Mannheimer S, Friedland G, Matts J, Child C, Chesney M: The consistency of adherence to antiretroviral therapy predicts biologic outcomes for human immunodeficiency virus-infected persons in clinical trials. Clin Infect Dis 2002, 34:1115-1121.

10. Paterson DL, Swindells S, Mohr J, Brester M, Vergis EN, Squier C, Wagener MM, Singh N: Adherence to protease inhibitor therapy and outcomes in patients with HIV infection. Ann Intern Med 2000, 133:21-30.

11. Haubrich RH, Little SJ, Currier JS, Forthal DN, Kemper CA, Beall GN, Johnson D, Dube MP, Hwang JY, McCutchan JA, California Collaborative Treatment Group: The value of patient-reported adherence to antiretroviral therapy in predicting virologic and immunologic response. AIDS 1999, 13:1099-1107

12. Knobel H, Codina C, Miro JM, Carmona A, Garcia B, Antela A, Gomez-Domingo MR, Arrizabalaga J, Iruin A, Laguna F, et al: The recommendations of GESIDA/SEFH/PNS for improving adherence to antiretroviral treatment. AIDS Study Group of the Spanish Society of Hospital Pharmacy and the National Plan on AIDS of the Minister of Health and Consumers. Enferm Infecc Microbiol Clin 2000, 18:27-39.

13. Mills EJ, Nachega JB, Buchan I, Orbinski J, Attaran A, Singh S, Rachlis B, Wu P, Cooper C, Thabane L, et al: Adherence to antiretroviral therapy in sub-Saharan Africa and North America: a meta-analysis. JAMA 2006, 296:679-690. 
14. Boden D, Hurley A, Zhang L, Cao Y, Guo Y, Jones E, Tsay J, Ip J, Farthing C,

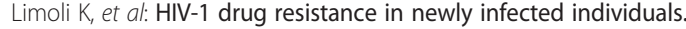
JAMA 1999, 282:1135-1141.

15. Hecht FM, Grant RM, Petropoulos CJ, Dillon B, Chesney MA, Tian H, Hellmann NS, Bandrapalli NI, Digilio L, Branson B, Kahn JO: Sexual transmission of an HIV-1 variant resistant to multiple reversetranscriptase and protease inhibitors. N Engl J Med 1998, 339:307-311.

16. Osterberg L, Blaschke T: Adherence to medication. N Engl J Med 2005, 353:487-497.

17. Stone VE, Hogan JW, Schuman P, Rompalo AM, Howard AA, Korkontzelou C, Smith DK: Antiretroviral regimen complexity, self-reported adherence, and HIV patients' understanding of their regimens: survey of women in the her study. J Acquir Immune Defic Syndr 2001, 28:124-131.

18. Sax PE, Gathe JC Jr: Beyond efficacy: the impact of combination antiretroviral therapy on quality of life. AIDS Patient Care STDS 2005, 19:563-576.

19. Chesney MA: Factors affecting adherence to antiretroviral therapy. Clin Inf Dis 2000, 30(S2):S171-S176.

20. Beach MC, Keruly J, Moore RD: Is the quality of the patient-provider relationship associated with better adherence and health outcomes for patients with HIV? J Gen Intern Med 2006, 21:661-665.

21. Roberts KJ: Physician-patient relationships, patient satisfaction, and antiretroviral medication adherence among HIV-infected adults attending a public health clinic. AIDS Patient Care STDS 2002, 16(1):43-50

22. Singh $N$, Squier $C$, Sivek $C$, Wagener $M$, Nguyen $M H$, Yu VL: Determinants of compliance with antiretroviral therapy in patients with human immunodeficiency virus: prospective assessment with implications for enhancing compliance. AIDS Care 1996, 8:261-269.

23. Gao X, Nau DP, Rosenbluth SA, Scott V, Woodward C: The relationship of disease severity, health beliefs and medication adherence among HIV patients. AIDS Care 2000, 12:387-398.

24. UNAIDS: UNAIDS report on the global AIDS epidemic. 2010. Available from: http://www.unaids.org/globalreport/Global_report.htm. (Accessed 29 December 2011).

25. Mosoko JJ, Akam W, Weidle PJ, Brooks JT, Aweh AJ, Kinge TN, Pals S, Raghunathan PL: Retention in an antiretroviral therapy programme during an era of decreasing drug cost in Limbe, Cameroon. J Int AIDS Soc 2011, 14:32.

26. Mahy S, Duong M, Huraux JM, Aurenche C, Ndong JG, Birguel J, Piroth L, Chavanet $P$ : Measure of effectiveness and adherence to antiretroviral therapy in HIV-infected patients in Cameroon. Med Mal Infect 2011, 41:176-180.

27. Kouanfack C, Laurent C, Peytavin G, Mawamba Nkene Y, Essomba C, Ciaf L, Ngolle M, Delaporte E, Calmy A, Mpoudi-Ngole' E, et al: Adherence to antiretroviral therapy assessed by drug level monitoring and self-report in Cameroon. J Acquir Immune Defic Syndr 2008, 48:216-219.

28. Boyer S, Marcellin F, Ongolo-Zogo P, Abega SC, Nantchouang R, Spire B, Moatti JP: Financial barriers to HIV treatment in Yaoundé, Cameroon: first results of a national cross-sectional survey. Bull World Health Organ 2009, 87:279-287.

29. Laurent C, Meilo H, Guiard-Schmid JB, Mapoure Y, Noel JM, M'Bangue M, Joko A, Rozenbaum W, Ntone FN, Delaporte E: Antiretroviral therapy in public and private routine health care clinics in Cameroon: lessons from the Douala antiretroviral (DARVIR) initiative. Clin Infect Dis 2005, 41:108-111.

30. Roux P, Kouanfack C, Cohen J, Marcellin F, Boyer S, Delaporte E, Carrieri P, Laurent $C$, Spire B: Adherence to antiretroviral treatment in HIV-positive patients in the Cameroon context: promoting the use of medication reminder methods. J Acquir Immune Defic Syndr 2011, 57(Suppl 1):S40-S43.

31. Rougemont M, Stoll BE, Elia N, Ngang P: Antiretroviral treatment adherence and its determinants in Sub-Saharan Africa: a prospective study at Yaounde Central Hospital, Cameroon. AIDS Res Ther 2009, 6:21.

32. Boyer S, Clerc I, Bonono CR, Marcellin F, Bile PC, Ventelou B: Non-adherence to antiretroviral treatment and unplanned treatment interruption among people living with HIV/AIDS in Cameroon: individual and healthcare supply-related factors. Soc Sci Med 2011, 72:1383-1392.

33. Mbopi-Keou FX, Dempouo Djomassi L, Monebenimp F: Etude des facteurs liés à l'observance au traitement antirétroviral chez les patients suivis à I'Unité de Prise En Charge du VIH/SIDA de I'Hôpital de District de Dschang, Cameroun. PAMJ 2012, 12:55
34. Newman J, Iriondo-Perez J, Hemingway-Foday J, Freeman A, Akam W, Balimba A, Kalenga L, Mbaya M, Mfangam Molu B, Mukumbi H, et al: Older adults accessing HIV care and treatment and adherence in the leDEA Central Africa cohort. AIDS Res Treat 2012, 2012:725713.

35. Freeman A, Newman J, Hemingway-Foday J, Iriondo-Perez J, Stolka K, Akam W, Balimba A, Kalenga L, Mbaya M, Mfangam Molu B, et al: Comparison of HIV-positive women with children and without children accessing HIV care and treatment in the leDEA Central Africa cohort. AIDS Care 2012, 24:673-679.

36. Mbuagbaw L, Thabane L, Ongolo-Zogo P, Lester R, Mills E, Volmink J, Yondo D, Essi M-J, Bonono-Momnougui R-C, Mba R, et al: The Cameroon Mobile Phone SMS (CAMPS) trial: a protocol for a randomized controlled trial of mobile phone text messaging versus usual care for improving adherence to highly active anti-retroviral therapy. Trials 2011, 12:5.

37. Boyer S, Protopopescu C, Marcellin F, Carrieri MP, Koulla-Shiro S, Moatti J-P, Spire B, Group tES: Performance of HIV care decentralization from the patient's perspective: health-related quality of life and perceived quality of services in Cameroon. Health Policy Plan 2011, 27:301-315.

38. von Elm E, Altman DG, Egger M, Pocock SJ, Gotzsche PC, Vandenbroucke JP: The Strengthening the Reporting of Observational Studies in Epidemiology (STROBE) statement: guidelines for reporting observational studies. J Clin Epidemiol 2008, 61:344-349.

39. Centers for Disease Control and Prevention: 1993 revised classification system for HIV infection and expanded surveillance case definition for AIDS among adolescents and adults. MMWR Recomm Rep 1992, 18:41(RR-17):1-19.

40. Lester RT, Ritvo P, Mills EJ, Kariri A, Karanja S, Chung MH, Jack W, Habyarimana J, Sadatsafavi M, Najafzadeh M, et al: Effects of a mobile phone short message service on antiretroviral treatment adherence in Kenya (WelTel Kenya1): a randomised trial. Lancet 2010, 376:1838-1845.

41. Pop-Eleches C, Thirumurthy H, Habyarimana JP, Zivin JG, Goldstein MP, de Walque D, Mackeen L, Haberer J, Kimaiyo S, Sidle J, et al: Mobile phone technologies improve adherence to antiretroviral treatment in a resource-limited setting: a randomized controlled trial of text message reminders. AIDS 2011, 25:825-834.

42. Hosmer DW, Lemeshow S: Applied logistic regression. New York: Wiley; 2000

43. Chung MH, Richardson BA, Tapia K, Benki-Nugent S, Kiarie JN, Simoni JM, Overbaugh J, Attwa M, John-Stewart GC: A randomized controlled trial comparing the effects of counseling and alarm device on HAART adherence and virologic outcomes. PLoS Med 2011, 8:e1000422.

44. Mbuagbaw L, Bonono-Momnougui RC, Thabane L: Considerations in using text messages to improve adherence to highly active antiretroviral therapy: a qualitative study among clients in Yaounde, Cameroon. HIV AIDS 2012, 4:45-50.

45. Farmer KC: Methods for measuring and monitoring medication regimen adherence in clinical trials and clinical practice. Clin Ther 1999, 21:1074-1090.

46. Ross-Degnan D, Pierre-Jacques M, Zhang F, Tadeg H, Gitau L, Ntaganira J, Balikuddembe R, Chalker J, Wagner AK: Measuring adherence to antiretroviral treatment in resource-poor settings: the clinical validity of key indicators. BMC Health Serv Res 2010, 10:42.

doi:10.1186/1742-6405-9-37

Cite this article as: Mbuagbaw et al:: Trends and determining factors associated with adherence to antiretroviral therapy (ART) in Cameroon: a systematic review and analysis of the CAMPS trial. AIDS Research and Therapy 2012 9:37. 